\title{
Evolution of the interaction between Runx2 and VDR, two transcription factors involved in osteoblasto]genesis
}

\author{
Sylvain Marcellini ${ }^{1,2^{*}}$, Carola Bruna², Juan P Henríquez ${ }^{1}$, Miguel Albistur ${ }^{1}$, Ariel E Reyes ${ }^{3,4}$, Elias H Barriga ${ }^{3,4}$,
} Berta Henríquez ${ }^{2}$, Martín Montecino²

\begin{abstract}
Background: The mineralized skeleton is a major evolutionary novelty that has contributed to the impressive morphological diversifications of the vertebrates. Essential to bone biology is the solidified extracellular matrix secreted by highly specialized cells, the osteoblasts. We now have a rather complete view of the events underlying osteogenesis, from a cellular, molecular, genetic, and epigenetic perspective. Because this knowledge is still largely restricted to mammals, it is difficult, if not impossible, to deduce the evolutionary history of the regulatory network involved in osteoblasts specification and differentiation. In this study, we focused on the transcriptional regulators Runx2 and VDR (the Vitamin D Receptor) that, in mammals, directly interact together and stabilize complexes of co-activators and chromatin remodellers, thereby allowing the transcriptional activation of target genes involved in extracellular matrix mineralization. Using a combination of functional, biochemical, and histological approaches, we have asked if the interaction observed between Runx2 and VDR represents a recent mammalian innovation, or if it results from more ancient changes that have occurred deep in the vertebrate lineage.
\end{abstract}

Results: Using immunohistochemistry and in situ hybridization in developing embryos of chick, frog and teleost fishes, we have revealed that the co-expression of Runx2 and VDR in skeletal elements has been particularly strengthened in the lineage leading to amniotes. We show that the teleost Runx2 orthologue as well as the three mammalian Runx1, Runx2 and Runx3 paralogues are able to co-immunoprecipitate with the VDR protein present in nuclear extracts of rat osteoblasts stimulated with 1 $\alpha, 25$-dihydroxyvitamin $\mathrm{D}_{3}$. In addition, the teleost Runx2 can activate the transcription of the mammalian osteocalcin promoter in transfection experiments, and this response can be further enhanced by $1 \alpha, 25$-dihydroxyvitamin $\mathrm{D}_{3}$. Finally, using pull-down experiments between recombinant proteins, we show that the VDR homologue from teleosts, but not from ascidians, is able to directly interact with the mammalian Runx2 homologue.

Conclusions: We propose an evolutionary scenario for the assembly of the molecular machinery involving Runx2 and VDR in vertebrates. In the last common ancestor of actinopterygians and sacropterygians, the three Runx paralogues possessed the potential to physically and functionally interact with the VDR protein. Therefore, 1 $\alpha, 25-$ dihydroxyvitamin $\mathrm{D}_{3}$ might have been able to modulate the transcriptional activity of Runx1, Runx2 or Runx3 in the tissues expressing VDR. After the split from amphibians, in the lineage leading to amniotes, Runx2 and VDR became robustly co-expressed in developing skeletal elements, and their regulatory interaction was incorporated in the genetic program involved in the specification and differentiation of osteoblasts.

\footnotetext{
* Correspondence: smarcellini@udec.cl

'Departamento de Biología Celular, Facultad de Ciencias Biológicas,

Universidad de Concepción, Casilla 160-C, Concepción, Chile
} 


\section{Background}

The formation and maintenance of the skeleton involves the specification and differentiation of specialized cell types, such as the osteoblasts, chondrocytes and osteoclasts [1-3]. The osteoblasts, of mesenchymal origin, are responsible for depositing the mineralized extracellular matrix of the bones. Their proliferation, survival, and physiology depend on a complex interplay between intrinsic and extrinsic signals. For example, if osteoblasts receive too few BMP signals, or if they fail to express the Runx2 and osterix transcription factors, their ability to differentiate into osteoblasts is largely compromised or abolished [4-6]. Runx2 was the first transcription factor identified as being essential for osteoblastogenesis $[5,7]$. It was later shown to act redundantly with its paralogue Runx3 during chondrogenesis [8]. Runx2 can either activate or repress transcription, depending on the nature of its cofactors, and on the regulatory architecture of the target promoter [Reviewed in [9-11]]. Although Runx2 has mainly been studied in mammals, we know that it is also expressed in chondrocytes and osteoblasts during the skeletogenesis of birds, frogs, teleost fishes and sharks [12-17]. In addition, morpholino knock-down approaches have demonstrated that Runx2 is required during chondrogenesis of Danio rerio and Xenopus tropicalis $[14,18]$. Taken together, these studies reveal a broad conservation of Runx2 function throughout osteichthyan vertebrates, a monophyletic group consisting of actinopterygians (such as teleost fishes) and sarcopterygians (such as tetrapods)[19].

Mammalian osteoblast specification and differentiation also rely on the activity of other transcription factors such as the Vitamin D Receptor (VDR) that belongs to the NR1I family of nuclear receptors [20,21]. The VDR is required for normal bone formation and regulates the transcription of target genes upon binding to its ligand, the $1 \alpha, 25$-dihydroxyvitamin $\mathrm{D}_{3}$ [22-25]. In the intestine, VDR and $1 \alpha, 25$-dihydroxyvitamin $\mathrm{D}_{3}$ play a pivotal role in the maintenance of bone mineralization and skeletal development through the regulation of proper calcium and phosphate absorption [26,27]. Importantly, the cellautonomous contribution of $V D R$ to osteoblastic differentiation has been demonstrated by several additional lines of evidence. First, the $1 \alpha, 25$-dihydroxyvitamin $\mathrm{D}_{3}$ enhances osteoblastic differentiation and stimulates the expression of VDR target genes coding for bone matrix components [28]. Second, osteoblasts express the Vitamin $\mathrm{D}$ receptor and also have the ability to synthesize 1 $\alpha, 25$-dihydroxyvitamin $\mathrm{D}_{3}$ [24,29]. Third, cultures of primary osteoblasts harvested from a $V D R$ knock-out mouse clearly exhibit a reduced mineralization potential [30]. Finally, the direct binding of the VDR to the promoters of osteoblast-specific genes like osteocalcin (ocn) and bone sialoprotein ( $b s p$ ) is required for chromatin remodeling and transcriptional activation induced by $1 \alpha$,25-dihydroxyvitamin $\mathrm{D}_{3}$ [31-33]. In this respect, it is relevant to note that the direct protein-protein interaction between VDR and Runx2 stabilizes transcriptional complexes at specific promoters, thereby contributing to osteogenesis [32]. In summary, a variety of experiments performed in adult tissues or in cell cultures have established VDR as an important osteoblast-specific transcription factor. However, the scarcity of developmental data and comparative studies clearly impede our understanding of the evolutionary mechanisms through which VDR became incorporated in the vertebrate skeletogenic regulatory network.

Indeed, changes in the regulatory interactions involved in cell specification and differentiation lie at the heart of the evolutionary process [34-36]. The functional experiments performed in mammalian osteoblasts have provided a detailed picture of the Runx2-dependent regulatory network supporting skeletogenesis. They revealed how the function of Runx2 is regulated at the transcriptional and post-translational level, and how distinct inputs converge on the Runx2 target genes. Yet, the lack of data from non-mammalian vertebrates renders difficult, if not impossible, to decipher how this skeletogenetic regulatory network emerged and evolved. In the present work, we focused our attention on a specific node of this complex network. In order to shed light on the evolutionary origin of the Runx2-VDR physical and functional interaction in osteoblasts, we have compared the function, the biochemical properties, and the expression patterns of their homologues from distantly related chordates. Based on our results, we propose that the three Runx paralogues and VDR had the potential to functionally and physically interact in the last common ancestor of osteichthyans, and most probably did so in tissues where both proteins were expressed, in the presence of $1 \alpha, 25$-dihydroxyvitamin $\mathrm{D}_{3}$. After the split from amphibians, in the lineage leading to amniotes, Runx2 and VDR became robustly coexpressed in developing skeletal elements, and their regulatory interaction was incorporated in the genetic program involved in the specification and differentiation of osteoblasts.

\section{Results}

Several studies performed in chondrichthyans and a variety of osteichthyans have demonstrated that the Runx2 expression in developing skeletal elements is highly conserved [12-17]. The evolution of the $V D R$ expression pattern is, however, less clear. The $V D R$ transcripts are known to be fairly ubiquitous in lamprey, teleost, and frog adult tissues analyzed by RT-PCR or 
Northern blot [37]. Because few studies have described the spatio-temporal expression pattern of $V D R$ during embryonic development [38], we decided to assess the degree of co-expression of Runx2 and VDR during skeletogenesis of distantly related oteichthyan vertebrate such as birds, amphibians and teleosts.

\section{VDR is robustly co-expressed with Runx2 in the} osteoblastic lineage of amniotes but not of amphibians The fact that cell cultures of chick calvaria show VDR expression before the onset of typical osteoblastic markers suggests that VDR could be co-expressed with Runx2 in the nuclei of osteoblastic precursors before cell differentiation and matrix mineralization [39]. To verify this possibility, we assessed the co-expression of Runx2 and VDR in developing skeletal elements of Gallus gallus at embryonic day (E)7 (Fig. 1a). We detected the VDR protein in the preosteoblastst present in the perichondrium as well as in the striated muscles, a situation reminiscent to what has been described in mammals (Fig. 1b) [40]. Therefore, VDR seems to be robustly expressed in the osteoblastic lineage of both intramembraneous and endochondral chick bones. To demonstrate the high degree of co-expression of the VDR and Runx2 proteins, we examined double stainings by confocal microscopy and observed that chick preosteoblasts are significantly enriched in both proteins (Fig. $1 \mathrm{e}-\mathrm{h})$. We further show that in developing chick skeletal elements Runx2 is strictly nuclear, while the VDR protein is evenly distributed in the cytoplasm and the nucleus, as expected (Fig. $1 \mathrm{i}-\mathrm{l}$ ).

Because birds are closely related to mammals, we next whished to analyze the expression of VDR in a tertrapod species that does not belong to the amniota. For this purpose, we analyzed endochondral bone of the amphibian Xenopus tropicalis at stage NF58 (Fig. 1c). Immunohistochemical staining revealed a strong expression in the hindlimb skeletal muscles, showing that the VDRspecific antibody can efficiently recognize the Xenopus epitope (Fig. 1d). However, in sharp contrast with the situation observed with chick embryos, no specific signal could be observed in differentiating osteoblasts of the periosteum (Fig. 1d). Although we cannot rule out the possibility that the VDR is expressed below detection level in frog osteoblasts, the strong positive reaction the skeletal muscle of Gallus and Xenopus supports the idea that, in amphibians, the VDR protein is not present in developing endochondral bones (compare Fig. 1b and 1d). Because the presence of mRNA coding for Runx 2 has already been demonstrated in the perichondrium and periosteum of several amphibian species $[15,41,42]$, the absence of VDR in these tissues rules out the possibility of a functional interaction between the two proteins.

\section{The teleost VDR and Runx2 are co-expressed in some skeletal elements}

In order to examine if Runx 2 and $V D R$ are co-expressed to some degree in developing skeletal elements of teleosts, we analyzed embryos from Danio rerio (Fig. 2). We first used RT-PCR to describe the temporal expression pattern of the Danio VDR gene, and revealed a maternal expression, the absence of transcripts in 24 hours post fertilization (hpf) larvae, and the presence of zygotic transcripts from $48 \mathrm{hpf}$ onward (Fig. 2e). We next compared the expression pattern of Runx2 and VDR in $72 \mathrm{hpf}$ larvae because at this stage both genes are expressed, and skeletal elements are actively developing $[43,44]$. As a result of a genomic duplication event that occurred in the teleost lineage, Danio rerio possesses two highly conserved Runx2 paralogues, named Runx2a and Runx2b [12]. We employed an in situ hybridization probe containing the complete open reading frame of $\operatorname{Runx} 2 b$ that is likely to also anneal to $R u n \times 2 a$ transcripts [12]. In this respect, it is important to stress out that at $72 \mathrm{hpf}$ the expression pattern of Runx $2 a$ only represents a fraction of the $R u n x 2 b$ positive cells [12]. We found that the expression patterns of Runx $2 b$ and $V D R$ differed in several respects. For instance, at this stage (72 hpf), Runx $2 b$ but not VDR transcripts are detected in the cleithrum, the fourth and fith branchial arches and quadrate (Fig. 2). Conversely, VDR but not Runx2b transcripts are detected in the inner plexiform layer (eye) and ventricle (heart) (Fig. 2). Most importantly, we also detected the presence of both mRNAs in several bones of the skull, such as the Meckel Cartilage (Lower Jaw), parasphenoid, palatoquadrate (Upper Jaw), and operculum (Fig. 2).

Altogether, these results reveal a clear difference between amniotes and other vertebrate species. While birds and mammals consistently show a robust co-localization of Runx2 and VDR in cells of the osteoblast lineage, these two proteins do not seem to be coexpressed in amphibian long bones, and the Runx2 and $V D R$ transcripts only partially overlap in skeletal elements of teleost fishes.

\section{The teleost Runx $2 b$ interacts with the $1 \alpha, 25$ - dihydroxyvitamin D3 signaling pathway in mammalian osteoblasts}

The co-expression of $V D R$ and Runx2 homologues in some skeletal elements of teleost embryos raises the possibility that Danio rerio Runx2 protein can functionally interact with the $1 \alpha, 25$-dihydroxyvitamin $\mathrm{D}_{3}$ signaling pathway in differentiating osteoblasts. Hence, we asked if the transcriptional activity of a teleost Runx2 homologue is sensitive to $1 \alpha, 25$-dihydroxyvitamin $D_{3}$. For this purpose, we used cultures of the rat ROS17/2.8 osteoblastic cell line known to increase the expression of osteoblast-specific genes in response to $1 \alpha, 25$-dihydroxyvitamin $\mathrm{D}_{3}$. In these cells, the ocn promoter 

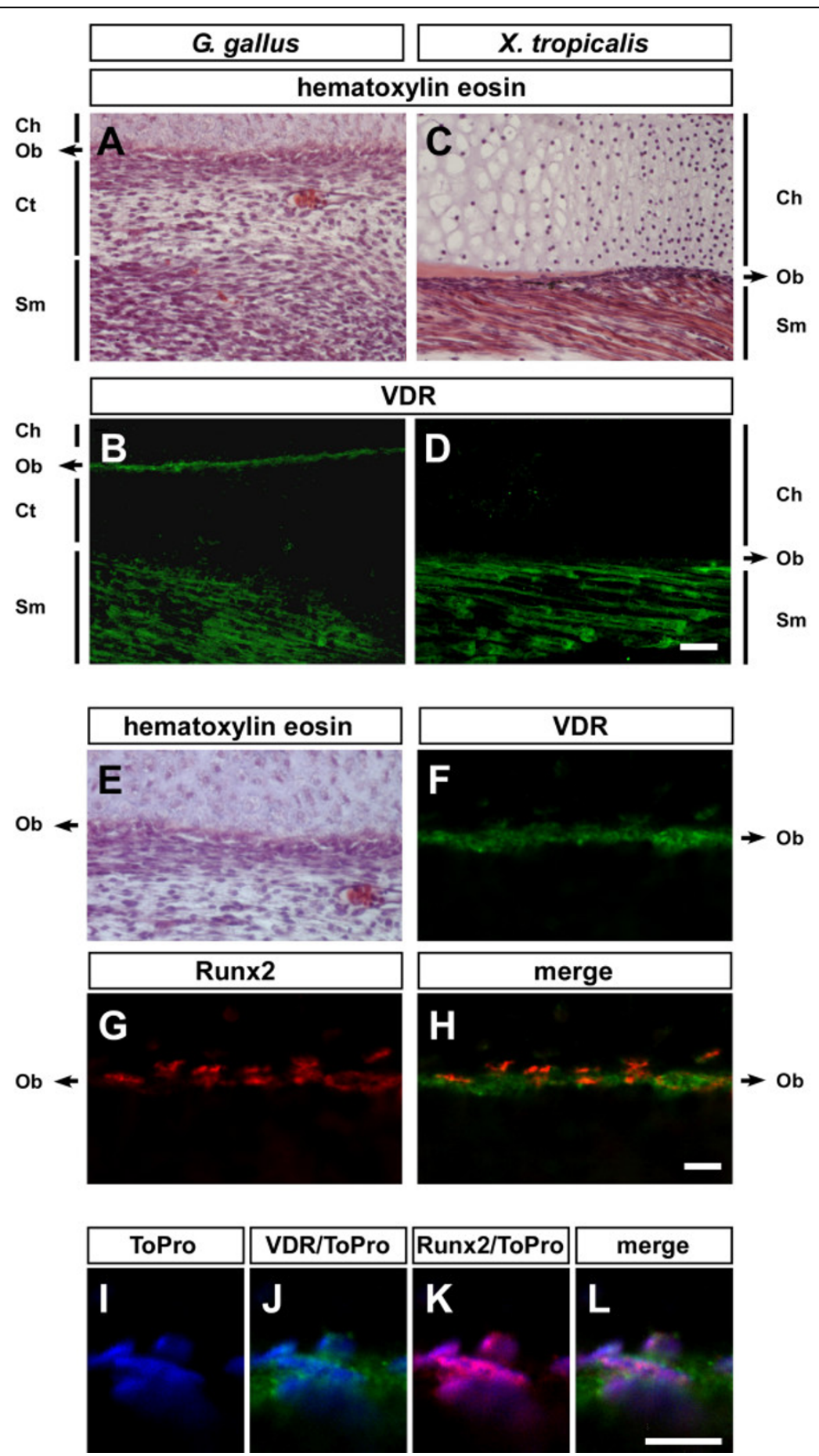

Figure 1 Runx2 and VDR are co-expressed in the osteoblastic lineage in amniotes but not in amphibians. The figure shows longitudinal sections of hindlimbs from E7 Gallus gallus (A-B, E-L) or from NF58 Xenopus tropicalis (C-D) specimens. (A) Hematoxilin staining showing the preosteoblasts of the developing perichondrium surrounded by hypertrophic chondrocytes, connective tissue and skeletal muscles. (B) Localization of the VDR protein in the skeletal muscles and cells of the osteoblastic lineage. (C) Hematoxilin staining showing the osteoblasts of the developing periosteum surrounded by hypertrophic chondrocytes and skeletal muscles. (D) Localization of the VDR protein in the skeletal muscles. (E) Hematoxilin staining of the perichondrium. (F-H) Fluorescent immunohistochemistry showing the localization of VDR (F), Runx2 (G) and the colocalization of both proteins $(\mathrm{H})$ in the perichondrium. (I-L) Higher magnification of the perichondrium cells. Nuclei are visualized using ToPro either alone (I, blue channel), with VDR (J, green channel), Runx2 (K, red channel), or both proteins (L). Abbreviations: Ch, hypertrophic chondrocytes; Ob, cells of the osteoblastic lineage; Ct, connective tissue; Sm, skeletal muscles. Scale bars represent 25 micrometers in a-d; and 10 micrometers in e-h and i-l. 

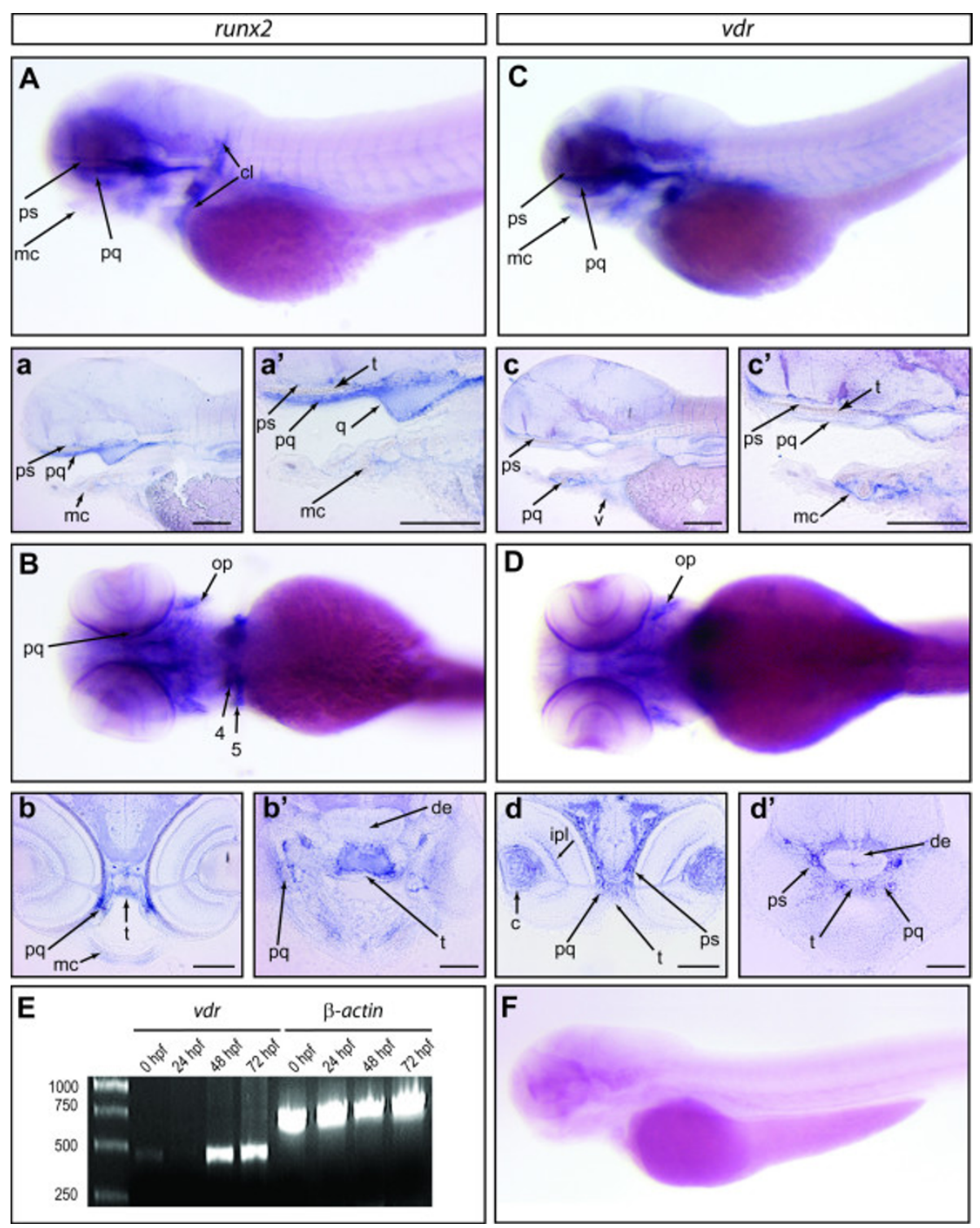

Figure 2 Expression pattern of Runx $\mathbf{2} b$ and VDR in Danio rerio. An in situ hybridization of a 72 hpf zebrafish embryo hybridized with a Run $\times 2 b$ antisense probe is shown in a lateral $(\mathbf{A})$ and ventral $(\mathbf{B})$ view. The images in $\mathbf{a}$ and $\mathbf{a}^{\prime}$ are sagittal sections of the specimen shown in $\mathbf{A}$. The images in $\mathbf{b}$ and $\mathbf{b}^{\prime}$ are transversal sections of the specimen shown in $\mathbf{B}$. An in situhybridization of a 72 hpf zebrafish embryo hybridized with a VDR antisense probe is shown in a lateral $(\mathbf{C})$ and ventral $(\mathbf{D})$ view. The images in $\mathbf{c}$ and $\mathbf{c}^{\prime}$ are sagittal sections of the specimen shown in C. The images in $\mathbf{d}$ and $\mathbf{d}^{\prime}$ are transversal sections of the specimen shown in D. (E) RT-PCR performed on CDNA from zebrafish embryos at 0,24 hpf, $48 \mathrm{hpf}$ and larvae at $72 \mathrm{hpf}$ with primers specific for VDR and $\beta$-actin. The molecular weight standard is shown on the left. (F) Lateral view of a $72 \mathrm{hpf}$ zebrafish larvae hybridized with a VDR sense probe. Abbreviations: c, crystalline; cl, cleithrum; de, diencephalon; ipl, inner plexiform layer; mc, meckel cartilage; op, operculum; pq, palate quadrate; ps, parasphenoid; q, quadrate; t, trabecula; v, ventricle; 4 and 5, the IV and V branchial cartilage territories, respectively. The scale bar in $a, a^{\prime}, b, b^{\prime}, c, c^{\prime}, d$ and $d^{\prime}$ represents 50 micrometers.

directly responds to the mammalian Runx2 protein, and this induction is further increased by the addition of $1 \alpha, 25$-dihydroxyvitamin $\mathrm{D}_{3}$ [32]. We found that the overexpression of the Danio rerio Runx $2 \mathrm{~b}$ stimulates the expression of a mammalian ocn reporter gene ( 1.5 fold increase), a response that is further enhanced by $1 \alpha, 25$ dihydroxyvitamin $\mathrm{D}_{3}$ treatment ( 2 fold increase, see Fig. $3 a, b)$. The magnitude of this effect was similar to control transfections performed in parallel with the mouse Runx2 homologue (not shown). This functional interaction suggests that the exogenous teleost Runx $2 b$ protein can physically interact with VDR-containing macromolecular complexes regulating the transcription of osteoblast-specific target genes. In agreement with this idea, we found that a GST fusion form of the Danio rerio Run $\mathrm{x} 2 \mathrm{~b}$ orthologue is able to interact with the 


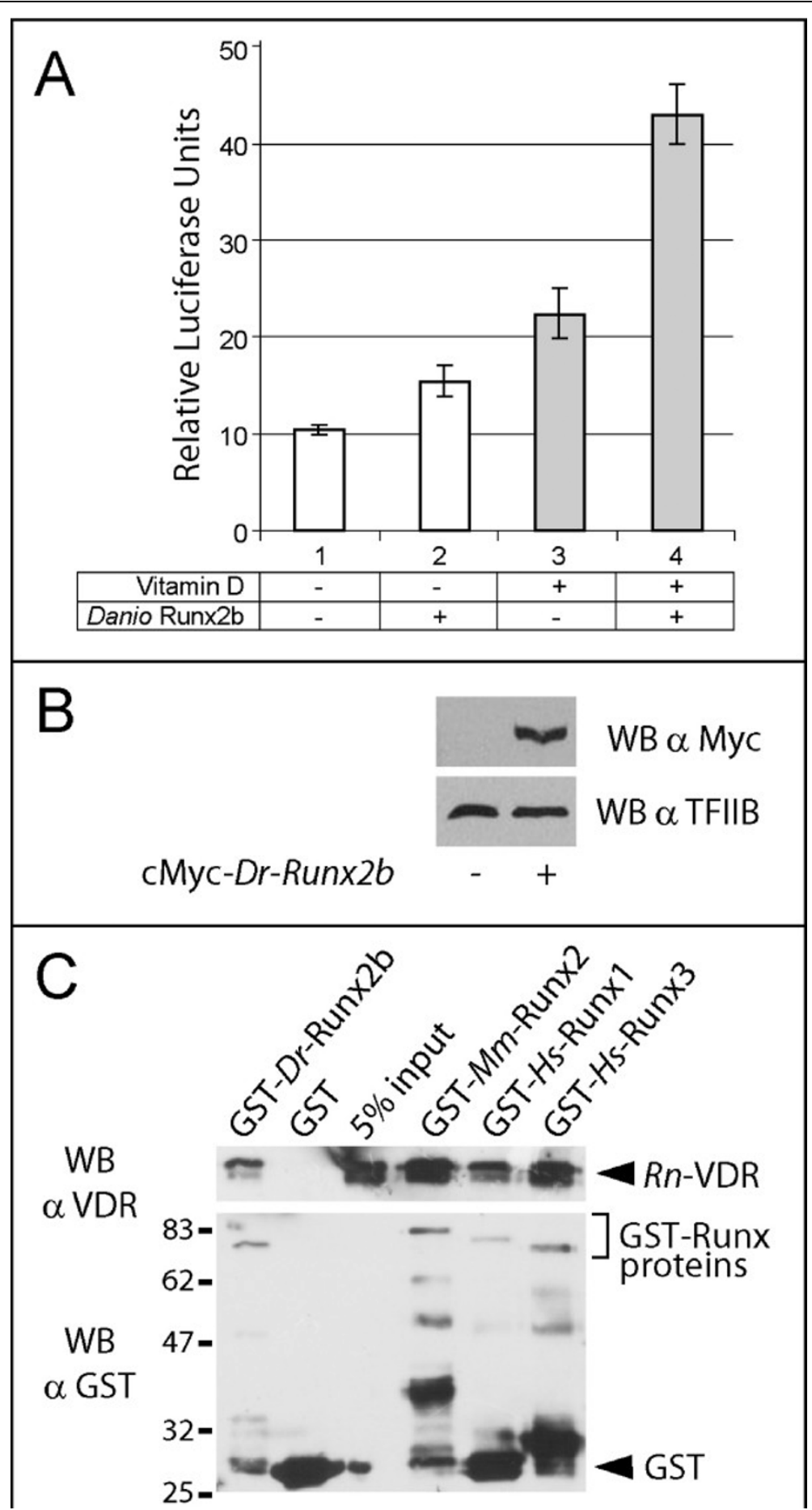

Figure 3 The teleost Runx $2 b$ is functional in mammalian osteoblasts and interacts with the 1 $\alpha, 25$-dihydroxyvitamin D3 pathway. (A) ROS17/2.8 osteoblasts were co-transfected for 12 hours with a Myc-tagged version of the Danio Runx $2 b$ homologue and the promoter of the rat osteocalcin driving the expression of the luciferase reporter gene. Cells were subsequently incubated for 18 hours in the absence (white bars) or in the presence (grey bars) of $1 \alpha, 25$-dihydroxyvitamin $D_{3}$ (Vitamin D) before being assayed for relative Luciferase activity. (B) Western blot performed on nuclear extracts from ROS17/2.8 cells transfected or not with the Danio Runx2b homologue. (C) Nuclear extracts (150 $\mu \mathrm{g})$ from ROS $17 / 2.8$ cells cultured in the presence of $10^{-8} \mathrm{M} 1 \alpha, 25$-dihydroxyvitamin $\mathrm{D}_{3}$ for $18 \mathrm{~h}$ were incubated with GST or with the indicated GST fusion proteins $(1.5 \mu \mathrm{g})$ previously bound to $20 \mu \mathrm{l}$ of glutathione-Sepharose beads. Precipitated VDR (upper panel) and GST-Runx (lower panel) proteins were then detected by Western blotting. The migration of molecular weight standards is indicated on the left. 
endogenous mammalian VDR obtained from nuclear extracts of immortalized rat osteoblasts (Fig. 3c). Likewise, in this assay, the three mammalian Runx paralogues are able to interact with VDR (Fig. 3c).

\section{The direct Runx2-VDR interaction is conserved between mammals and teleosts but not between mammals and tunicates}

We subsequently used GST-pull down between purified recombinant proteins to assay the degree of evolutionary conservation of the direct physical interaction previously described between the mammalian Runx2 and VDR [32]. As shown on fig. 4a, the GST-Runx2 proteins from teleosts or mammals can interact, albeit weakly, with the mammalian VDR in vitro. We interpret the weak interaction in vitro as the requirement of additional cofactors, such as P300 or SRC1, that form macromolecular complexes with the Runx2 and VDR proteins bound to their native target genes $[22,32]$. Hence, this result supports the idea that the ability of Runx 2 to directly interact with a mammalian VDR is well conserved between distantly related osteichthyan vertebrates. To verify if, reciprocally, the teleost VDR protein also bears the ability to directly recognize various Runx2 homologues, we produced a recombinant form of the Danio rerio VDR homologue. In GST pull down assays, the Danio VDR protein is able to recognize the Runx2 homologues from mammals and teleosts, thereby confirming that the direct Runx2-VDR interaction was possible in the ancestral osteichthyan vertebrate (Fig. 4b). Finally, to assess if the interaction between VDR and Runx homologues is shared with invertebrates, we used an outgroup nuclear receptor from the tunicate Ciona intestinalis that is most closely related to the vertebrate VDR [hereafter referred to as Ci-VDR, see $[20,21,45]] . C i-V D R$ is unable to interact with the mammalian GST-Runx2 protein (Fig. 4c). Lowering the stringency of the reaction buffer did not result in any detectable interaction (not shown). Taken together, these findings suggest that the Runx2-VDR interaction is highly conserved between osteichthyan species, but that the invertebrate VDR orthologues are too divergent to be able to interact with vertebrate Runx 2 proteins.

\section{Discussion}

With a few recent exceptions, most of our knowledge regarding the genetic basis of osteoblast specification and differentiation comes from experiments performed in mammals $[3,11,46-48]$. In the present study, we investigated the evolutionary origin of one component of the regulatory network involved in osteogenesis: the functional and physical interaction between the Runx2 and VDR transcription factors [32].

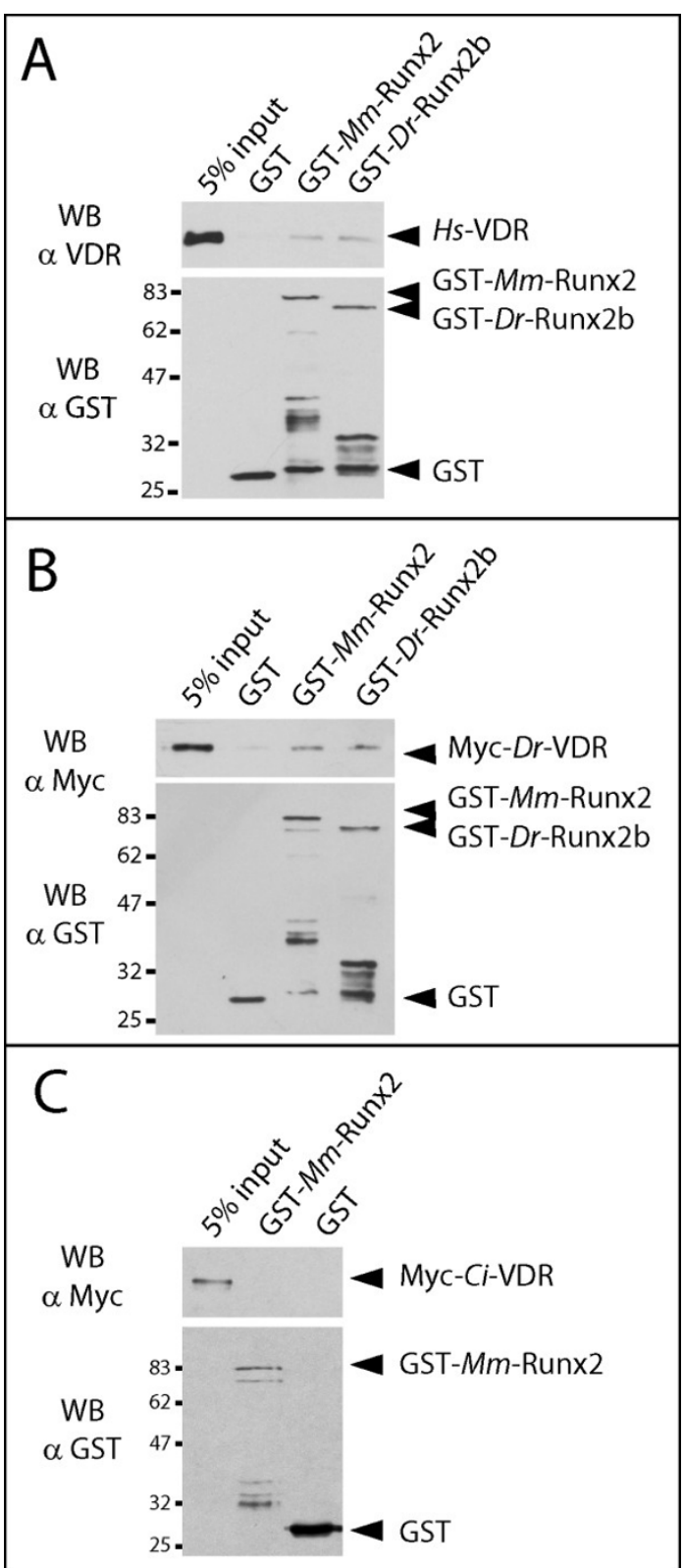

Figure 4 The Runx-VDR interaction is well conserved between osteichthyan vertebrate species. GST or the indicated GST-Runx2 fusion proteins $(1.5 \mu \mathrm{g})$ previously bound to $20 \mu \mathrm{l}$ of glutathioneSepharose beads were incubated with the recombinant VDR homologue from Homo sapiens (A) or Danio rerio (B). The Danio rerio VDR protein is not recognized by the anti-VDR antibody (not shown) and was therefore tagged with an N-terminal Myc epitope. Precipitated VDR (upper panel) and GST-Runx2 (lower panel) proteins were then detected by Western blotting. (C) The recombinant VDR homologue from Ciona intestinalis (bearing a Myc epitope in its N-terminal) was incubated with GST or the indicated GST fusion proteins $(1.5 \mu \mathrm{g})$ previously bound to $20 \mu \mathrm{l}$ of glutathione-Sepharose beads. Precipitated VDR (upper panel) and GST-Runx2 (lower panel) proteins were then detected by Western blotting. Abbreviations: Dr, Danio rerio; Mm, Mus musculus; Hs, Homo sapiens; Ci, Ciona intestinalis. The migration of molecular weight standards is indicated on the left. 
Expression analysis revealed a clear difference between amniotes and non-amniote vertebrates. While Runx2 and VDR are robustly co-expressed in nuclei of the osteoblastic lineage of mammals [32] and birds (this study), we found that the two proteins are unlikely to be co-expressed in amphibians and only partially overlap in skeletal elements of teleosts. This observation suggests a relatively recent recruitment of the VDR in the bones of amniotes representative (Fig. 5). Hence, although all vertebrate species possess morphologically similar cells named osteoblasts, important regulatory differences might progressively evolve in specific lineages and modify the transcriptional network controlling the specification and differentiation of this cell type. From our results it is tempting to propose that the VDR plays a direct, cell autonomous, role in all osteoblasts of amniotes, but not in amphibians (Fig. 5). In Danio rerio, $1 \alpha, 25$-dihydroxyvitamin D3 increases mineralization [49]. Our results suggest that this hormone regulates bone mineralization indirectly (via the control of calcium and phosphate homeostasis in intestinal cells), but also cell-autonomously, in the osteoblasts of the specific skeletal elements where Runx2 and VDR are coexpressed (e.g. the parasphenoid and the operculum). A broader sampling of actinopterygian, sacrcopterygian as well as chondrichthyan species would provide valuable information regarding this issue.

Using in vitro GST pull-down assays, we observed that the mammalian and teleost VDR proteins can interact with various Runx homologues. In particular, the interaction is conserved with the two mammalian paralogues (Runx1 and Runx3) and with the teleost orthologue (Danio rerio Runx2). These experiments reveal that the interaction domains between the ancestral VDR and Runx proteins were already compatible in the last common ancestor of all osteichthyan vertebrates, and have remained well conserved. In agreement with these data, we confirmed that the Runx2b protein from teleosts is functional in mammalian osteoblastic cells and can be further stimulated by the addition of the VDR ligand. These results suggest that this hormone can stabilize Runx2-VDR complexes on the promoter of specific target genes in teleost osteoblasts.

We failed to detect an interaction between the VDR homologue from tunicates and a vertebrate Runx2 orthologue. In this regard, it is relevant to point out that the $C i$-VDR transcription factor differs from its vertebrate homologues in many other respects, as it is unable to activate reporter genes and to interact with $1 \alpha, 25$ dihydroxyvitamin $\mathrm{D}_{3}[21,45,50,51]$. Hence, after the split from tunicates, the ancestral vertebrate VDR underwent dramatic structural modifications, both in the C-terminal ligand-binding domain $[21,51]$ and in the Runx2binding domain mapped to the $\mathrm{N}$-terminal region [32].
It is possible, but unproven, that the Runx and VDR orthologues are undergoing a constant co-evolutionary process and interact together in tunicates (Fig. 5).

In sharp contrast with the highly conserved skeletonspecific expression of Runx2, the transcripts and protein product of the $V D R$ gene are detected in a broad variety of lamprey, teleost and amphibian adult organs $[37,38,45,50]$. One might stipulate that the functional cooperation observed between VDR and Runx 2 can be extended to the other vertebrate Runx paralogues that are co-expressed with the VDR. Therefore, in addition to osteoblasts, it is possible that $1 \alpha, 25$-dihydroxyvitamin $\mathrm{D}_{3}$ signaling directly integrates the Runx-dependent regulatory networks involved in the specification of many vertebrate tissues where VDR is co-expressed with Runx1 or Runx3. Indeed, the fairly ubiquitous expression of the VDR might have increased its chances of being co-expressed with (and to interact with) any of the three Runx paralogues. In this respect, it is interesting to correlate the expression of Runx and VDR homologues in endodermal tissues. On the one hand, Runx orthologues of nematode, sea urchin, amphioxus and mammals (Runx3) are expressed in the gut [52-55], suggesting an ancient endodermal expression inherited from the urbilateria. On the other hand, $V D R$ is expressed in the intestine of teleosts [37], lampreys [45], frogs [50], birds [56] and mammals [57]. It is tempting to propose that shortly after its emergence, the VDR protein was co-expressed in the gut with Runx3 (Fig. 5). Once the first Runx-VDR regulatory interaction established, it would have been free to spread to the other Runx transcription factors and their tissue-specific target genes by exaptation and regulatory rewiring $[58,59]$.

\section{Conclusions}

In summary, we propose that the molecular machinery involving Runx2 and VDR in osteoblastic cells exists at least since the emergence of the osteichthyans, but has subsequently been strengthened in the lineage leading to amniotes. The widespread VDR distribution might have facilitated the co-expression with the Runx paralogues, and contributed to the emergence of the Runx-VDR physical and functional interaction in a variety of tissues. Osteoblasts from distantly-related vertebrate species secrete mineralized matrix and exhibit a similar morphology [60]. Yet, in spite of these shared characters, genomic turnover continuously creates, eliminates and modifies genes coding for bone matrix proteins, a phenomenon called phenogenetic drift [61]. Our results suggest that, likewise, the osteoblast-specific regulatory network has steadily been evolving during the vertebrate radiations. Although the essential Runx2-dependent regulatory kernel has remained highly conserved, it should not come as a surprise if, between species, 


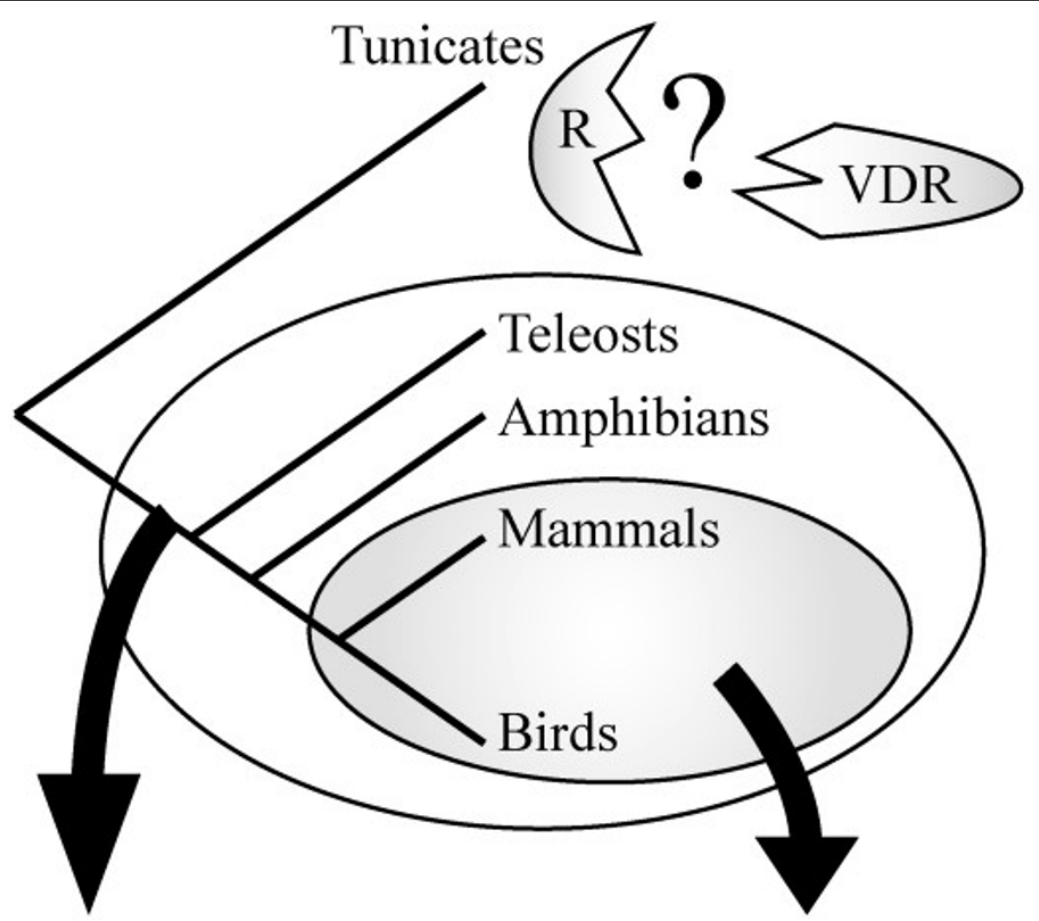

Osteichthyans: hypothetical ancestral situation

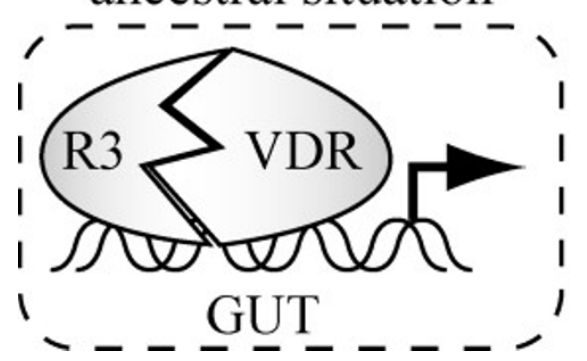

Amniotes: Robust co-expression of Runx2 and VDR in osteoblasts

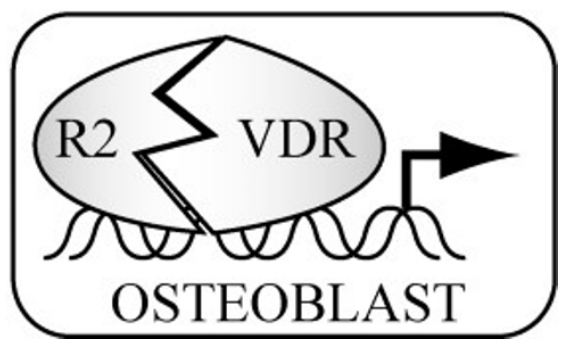

Figure $5 \mathrm{~A}$ model for the evolution of the Runx2-VDR interaction. A schematic phylogenetic tree showing the evolutionary relationship of invertebrate (tunicates) and vertebrate (osteichthyans) chordates is shown. It is not known if the tunicate Runx (R) and VDR horthologues can interact together (question mark). As Runx3 (R3) and VDR are strongly co-expressed in the gut of many osteichthyan species, their interaction might represent an ancestral, gut-specific, regulatory module. The physical and functional interaction between Runx2 (R2) and VDR probably plays a minor role during osteichthyan skeletogenesis (i.e. only in some species or in a subset of skeletal elements). We propose here that it was particularly strengthened in amniotes, once the VDR became robustly expressed in osteoblasts.

osteoblastogenesis is modulated by a plethora of different transcription factors, signaling pathways, and ligands, such as the 1 $\alpha, 25$-dihydroxyvitamin D3.

\section{Methods}

Immunohistochemistry

Gallus gallus E7 and Xenopus tropicalis stage 58 [62] hindlimbs were dissected out and fixed for three days in Bouin (14 volumes of picric acid, 5 volumes of formaldehyde $37 \%$ and 1 volume of glacial acetic acid). Samples were subsequently embedded in paraffin, sectioned at a seven micrometer thickness, mounted on glass slides and stained following a classical hematoxylin eosin procedure. For immunohistochemistry, hindlimbs from Gallus gallus E7 embryos and from Xenopus tropicalis stage 58 tadpoles were removed, mounted in OCT (Sakura Finetek, Torrance, CA, USA) and quickly frozen in isopentane cooled with liquid nitrogen, as described [63]. Cryosections (20 micrometer) were immunostained with primary antibodies diluted 1:100 in blocking solution (1\% BSA in Dulbecco's phosphate buffer saline; D-PBS) $12-15 \mathrm{~h}$ at $4^{\circ} \mathrm{C}$. Antibodies were C-20 (rabbit polyclonal anti-rat VDR, Santa Cruz Biotechnology) and a mouse monoclonal anti-Runx 2 , kindly provided by the 
laboratory of Dr. Gary Stein. Control experiments performed in the absence of primary antibodies gave negative results (not shown). Corresponding alexa488 and alexa546-conjugated secondary immunoglobulins (Invitrogen) were incubated for $2 \mathrm{~h}$ at RT. Nuclei cells were counterstained with TO-PRO-3 iodide (Invitrogen). Samples were subsequently mounted with aqueous medium for fluorescence (Sigma). Images were acquired with a laser confocal Nikon Eclipse TE2000-U microscope.

\section{In situ hybridization and RT-PCR on Danio rerio embryos}

Danio rerio embryos were raised at $28^{\circ} \mathrm{C}$ and fixed for in situ hybridization in $4 \%$ paraformaldehyde. Hybridization reactions were performed as previously described [64]. The Danio rerio VDR probe covered the region coding for the ligand binding domain [65]. Embryos were mounted in glycerol, observed under a Leica MZ12.5 stereomicroscope and photographs were taken with a Leica DC300F digital camera.

The mRNA for expression studies was extracted from embryos or larvae at different stages of development $(0$, 24, 48 and $72 \mathrm{hpf}$ ) using the Trizol Reagent according to the manufacturer's indications (Invitrogen). Reverse transcription was performed with the SuperScript II (Invitrogen) according to the manufacturers' instructions. As an internal control, we used $\beta$-actin primers: Forward 5'-TTC TGG TCG GTA CTA CTG GTA TTG TG-3' and reverse 5'-ATC TTC ATC AGG TA- GTC TGT CAG GT-3'. The sequences of the VDR primers were as follow: Forward 5'-TCA CTG ATG GAT CTG ATG GC-3' and reverse 5'-CTG AAT CTG ACG AAG TCG GA-3'.

\section{Transfection and luciferase assay}

The rat ROS 17/2.8 osteoblastic cells were cultured as described previously [32]. Cells were plated in 24-well plates and transiently transfected with the Rattus norgevicus osteocalcin-luciferase reporter (pOC-LUC, $50 \mathrm{ng} /$ well), the renilla internal control (pSV40-renilla, $2.5 \mathrm{ng} /$ well) and a Myc tagged version of the full length Danio rerio Runx2 open reading frame under the control of the CMV promoter (100 ng/well). The total amount of transfected DNA was maintained at $650 \mathrm{ng} /$ well with pBluescript. ROS $17 / 2.8$ cells were transfected with Lipofectamine Plus reagent (Invitrogen) according to the manufacturer's instructions. Six hours after transfection, $1 \alpha, 25$-dihydroxyvitamin $\mathrm{D}_{3}$ was added to the medium at a final concentration of $10^{-8} \mathrm{M}$. Cells were harvested $24 \mathrm{~h}$ after transfection and assayed for Luciferase and Renilla activity using the Luciferase Assay System (Promega) in a TD20/20 luminometer (Turner Designs). The efficiency of the overexpression was verified by Western blots on nuclear extracts prepared from transfected cells.

\section{GST-pull down assays}

The proteins containing the $\mathrm{N}$-terminal glutathione $\mathrm{S}$ transferase (GST) fused in frame to the Runx homologues were obtained by expression in Escherichia coli BL21 strain as previously reported [32]. GST-free proteins were obtained by cleaving GST-VDR or GSTRunx2 orthologues with $25 \mathrm{U}$ of Thrombin (Amersham Biosciences) at $4^{\circ} \mathrm{C}$ overnight. Nuclear extracts were prepared from 15 plates of confluent ROS 17/8.2 previously treated with $10^{-8} \mathrm{M} 1 \alpha, 25$-dihydroxyvitamin $\mathrm{D}_{3}$ for 18 $\mathrm{h}$. The plates were placed on ice for $10 \mathrm{~min}$, and then washed with $10 \mathrm{ml}$ of cold PBS. Cells were collected with a scrapper in $15 \mathrm{ml}$ of cold PBS with Complete protease inhibitor Cocktail (Roche), and centrifuged at $2000 \mathrm{rpm}$ for $5 \mathrm{~min}$ at $4^{\circ} \mathrm{C}$. The Cells were resuspended and incubated on ice for $5 \mathrm{~min}$ in 5 volumes of pellet equivalent of buffer A (10 mM HEPES pH7,9; $1,5 \mathrm{mM}$ $\mathrm{MgCl} 2 ; 10 \mathrm{mM} \mathrm{KCl} ; 1 \mathrm{mM}$ DTT and $1 \times$ Protease inhibitor). Cells were lysed using a Dounce homogenizer and centrifuged at $3000 \mathrm{rpm}$ for $15 \mathrm{~min}$ at $4^{\circ} \mathrm{C}$. Pelleted nuclei were washed with $5 \mathrm{ml}$ of cold buffer A, centrifuged at $12000 \mathrm{rpm}$ for $10 \mathrm{~min}$ at $4^{\circ} \mathrm{C}$, resuspended in $100 \mu \mathrm{L}$ of cold buffer C (20 mM HEPES pH7,9; $1,5 \mathrm{mM}$ $\mathrm{MgCl} 2 ; 420 \mathrm{mM} \mathrm{KCl}$; 0,2 mM EDTA; $1 \mathrm{mM}$ DTT; $1 \times$ Complete Protease inhibitor), and incubated for $1 \mathrm{~h}$ at $4^{\circ} \mathrm{C}$ with gentle agitation. After centrifuging at 12500 $\mathrm{rpm}$ for $15 \mathrm{~min}$ at $4^{\circ} \mathrm{C}$ the supernatant (nuclear extracts) was collected, quantified using a classical Bradford assay, and rapidly frozen with $25 \%$ glycerol. The GST-pull down assays were performed with $25 \mu \mathrm{l}$ of Glutation Sepharose resin (Pharmacia Biotechnologies). $1 \mu \mathrm{g}$ of GST, Runx2-GST (or VDR-GST) fusion proteins were incubated in $400 \mu \mathrm{l}$ of binding buffer $(20 \mathrm{mM}$ Tris $\mathrm{pH}$ 8.0, $100 \mathrm{mM} \mathrm{KCl}, 0.5 \% \mathrm{NP}-40,10 \mathrm{mM}$ EDTA, $0.05 \mathrm{mM}$ PMSF, $1 \mathrm{mM}$ DTT) for $30 \mathrm{~min}$ at $4^{\circ} \mathrm{C}$ with gentle agitation. $1.5 \mu \mathrm{g}$ of pure recombinant VDR (or Runx2) proteins were added in a final volume of $500 \mu \mathrm{L}$ of the binding buffer containing $0.5 \%$ of non-fat milk, and were subsequently incubated for $2 \mathrm{~h}$ at $4^{\circ} \mathrm{C}$ with gentle agitation. The reactions were washed four times with $500 \mu \mathrm{L}$ binding buffer for $5 \mathrm{~min}$ at $4^{\circ} \mathrm{C}$. After the last centrifugation, the resin was resuspended in loading buffer $(100 \mathrm{mM}$ Tris-Cl pH 6.8, 4\% p/v SDS, $0.15 \% \mathrm{v} / \mathrm{v}$ bromofenol blue, $20 \% \mathrm{v} / \mathrm{v}$ glycerol, $200 \mathrm{mM} \mathrm{DTT}$ ) and incubated for $5 \mathrm{~min}$ at $95^{\circ} \mathrm{C}$. The proteins that were retained with the resin were run in a $10 \%$ acrylamide SDS-PAGE and revealed by Western blotting with specific antibodies against VDR (C-20, Santa Cruz Biotechnology), GST (Pharmacia Biotech) and cMyc (9E10, Santa Cruz Biotechnology). The accession numbers of the cDNAs coding for the proteins used in this study are: Homo sapiens Runx1 (NM_001754), Mus musculus Runx2 (NM_004348), Homo sapiens Runx3 (NM_004350.2), Danio rerio Runx2 (AY443097), Homo 
sapiens VDR (NM_000376) and Ciona intestinalis VDRPXR homologue (AB210742). The Danio rerio full length $V D R$ clone was reconstituted by PCR using overlapping 5' and 3' regions as templates. The 3' region corresponded to the ligand binding domain [described in [65]]. The 5' region coding for the DNA binding domain was obtained by RT-PCR using $72 \mathrm{hpf}$ cDNA as a template (forward primer 5'-TCA CTG ATG GAT CTG ATG GC-3' and reverse primer 5'-CTG AAT CTG ACG AAG TCG GA-3').

\section{Acknowledgements}

Reagents were kindly provided by Leonor Cancela (Danio rerio Runx2 CDNA); Natacha Rochel and Dino Moras (Danio rerio Vdr cDNA coding for the ligand binding domain); Yutaka Satou, Yuji Kohara and Noriyuki Satoh (Ciona intestinalis VDR CDNA) and Gary Stein (mouse monoclonal anti-Runx2 antibody). We are grateful to Enrique Silva for help with histological work. This study was supported by a Research Ring grant (PBCT ACT-044) to MM; a Research Ring grant (PBCT ACT-02) to JPH; a FONDECYT Regular grant (1095128) to AER; a FONDECYT postdoctoral grant (3060063) and a FONDECYT regular grant (1080021) to SM. The authors declare that they have no competing financial or other interest in relation to this work.

\section{Author details}

'Departamento de Biología Celular, Facultad de Ciencias Biológicas, Universidad de Concepción, Casilla 160-C, Concepción, Chile. ${ }^{2}$ Departamento de Bioquímica y Biología Molecular, Facultad de Ciencias Biológicas, Universidad de Concepción, Casilla 160-C, Concepción, Chile. ${ }^{3}$ Facultad de Ciencias de la Salud, Universidad Diego Portales, Av Ejército 141, piso 4, Santiago, Chile. ${ }^{4}$ Current address: Laboratorio de Biología del Desarrollo, Facultad de Ciencias Biológicas, Universidad Andrés Bello, Av República 217, Piso 3, Santiago, Chile.

\section{Authors' contributions}

SM carried out pull down experiments with nuclear extracts, participated to transfection experiments and to immunohistochemical staining of chick and frog long bones, and wrote the paper. SM and MM designed the study and analyzed the data. CB carried out pull down experiments with recombinant proteins. $\mathrm{BH}$ participated in the cell cultures and in transfection experiments. $\mathrm{JPH}$ and MA participated in the immunohistochemical staining of chick and frog long bones. AER and EHB performed the RT-PCR and in situ hybridization experiments with Danio rerio. All authors read and approved the final manuscript.

Received: 2 September 2009 Accepted: 17 March 2010 Published: 17 March 2010

\section{References}

1. Mackie EJ, Ahmed YA, Tatarczuch L, Chen KS, Mirams M: Endochondral ossification: how cartilage is converted into bone in the developing skeleton. Int J Biochem Cell Biol 2008, 40(1):46-62.

2. Bar-Shavit Z: The osteoclast: a multinucleated, hematopoietic-origin, bone-resorbing osteoimmune cell. J Cell Biochem 2007, 102(5):1130-1139.

3. Marie PJ: Transcription factors controlling osteoblastogenesis. Arch Biochem Biophys 2008, 473(2):98-105.

4. Bandyopadhyay A, Tsuji K, Cox K, Harfe BD, Rosen V, Tabin CJ: Genetic Analysis of the Roles of BMP2, BMP4, and BMP7 in Limb Patterning and Skeletogenesis. PLOS Genet 2006, 2(12):e216.

5. Komori T, Yagi H, Nomura S, Yamaguchi A, Sasaki K, Deguchi K, Shimizu Y, Bronson RT, Gao YH, Inada M, et al: Targeted disruption of Cbfa1 results in a complete lack of bone formation owing to maturational arrest of osteoblasts. Cell 1997, 89(5):755-764.

6. Nakashima K, Zhou X, Kunkel G, Zhang Z, Deng JM, Behringer RR, de Crombrugghe $B$ : The novel zinc finger-containing transcription factor osterix is required for osteoblast differentiation and bone formation. Cell 2002, 108(1):17-29.
7. Otto F, Thornell AP, Crompton T, Denzel A, Gilmour KC, Rosewell IR, Stamp GW, Beddington RS, Mundlos S, Olsen BR, et al: Cbfa1, a candidate gene for cleidocranial dysplasia syndrome, is essential for osteoblast differentiation and bone development. Cell 1997, 89(5):765-771.

8. Yoshida CA, Yamamoto H, Fujita T, Furuichi T, Ito K, Inoue K, Yamana K, Zanma A, Takada K, Ito Y, et al: Runx2 and Runx3 are essential for chondrocyte maturation, and Runx2 regulates limb growth through induction of Indian hedgehog. Genes Dev 2004, 18(8):952-963.

9. Lian JB, Stein GS, Javed A, van Wijnen AJ, Stein JL, Montecino M, Hassan MQ, Gaur T, Lengner CJ, Young DW: Networks and hubs for the transcriptional control of osteoblastogenesis. Rev Endocr Metab Disord 2006, 7(1-2):1-16.

10. Zaidi SK, Young DW, Choi JY, Pratap J, Javed A, Montecino M, Stein JL, van Wijnen AJ, Lian JB, Stein GS: The dynamic organization of gene-regulatory machinery in nuclear microenvironments. EMBO Rep 2005, 6(2):128-133.

11. Komori T: Regulation of skeletal development by the Runx family of transcription factors. J Cell Biochem 2005, 95(3):445-453.

12. Flores MV, Tsang WW, Hu W, Kalev-Zylinska M, Postlethwait J, Crosier P, Crosier K, Fisher S: Duplicate zebrafish runx2 orthologues are expressed in developing skeletal elements. Gene Expr Patterns 2004, 4(5):573-581.

13. Inohaya K, Kudo A: Temporal and spatial patterns of cbfal expression during embryonic development in the teleost, Oryzias latipes. Dev Genes Evol 2000, 210(11):570-574

14. Kerney R, Gross JB, Hanken J: Runx2 is essential for larval hyobranchial cartilage formation in Xenopus laevis. Dev Dyn 2007, 236(6):1650-1662.

15. Moriishi T, Shibata Y, Tsukazaki T, Yamaguchi A: Expression profile of Xenopus banded hedgehog, a homolog of mouse Indian hedgehog, is related to the late development of endochondral ossification in Xenopus laevis. Biochem Biophys Res Commun 2005, 328(4):867-873.

16. Stricker S, Fundele R, Vortkamp A, Mundlos S: Role of Runx genes in chondrocyte differentiation. Dev Biol 2002, 245(1):95-108.

17. Hecht J, Stricker S, Wiecha U, Stiege A, Panopoulou G, Podsiadlowski L, Poustka AJ, Dieterich C, Ehrich S, Suvorova J, et al: Evolution of a core gene network for skeletogenesis in chordates. PLoS Genet 2008, 4(3): e1000025

18. Hassan MQ, Tare RS, Lee SH, Mandeville M, Morasso Ml, Javed A, van Wijnen AJ, Stein JL, Stein GS, Lian JB: BMP2 Commitment to the Osteogenic Lineage Involves Activation of Runx2 by DLX3 and a Homeodomain Transcriptional Network. J Biol Chem 2006, 281(52):40515-40526

19. Zhu M, Zhao W, Jia L, Lu J, Qiao T, Qu Q: The oldest articulated osteichthyan reveals mosaic gnathostome characters. Nature 2009, 458(7237):469-474.

20. Bertrand S, Brunet FG, Escriva H, Parmentier G, Laudet $V$, RobinsonRechavi M: Evolutionary genomics of nuclear receptors: from twenty-five ancestral genes to derived endocrine systems. Mol Biol Evol 2004, 21(10):1923-1937.

21. Reschly EJ, Bainy AC, Mattos JJ, Hagey LR, Bahary N, Mada SR, Ou J, Venkataramanan $R$, Krasowski MD: Functional evolution of the vitamin D and pregnane $\mathrm{X}$ receptors. BMC Evol Biol 2007, 7:222.

22. Montecino M, Stein GS, Cruzat F, Marcellini S, Stein JL, Lian JB, van Wijnen AJ, Arriagada G: An architectural perspective of vitamin D responsiveness. Arch Biochem Biophys 2007, 460(2):293-299.

23. Kraichely DM, MacDonald PN: Transcriptional activation through the vitamin D receptor in osteoblasts. Front Biosci 1998, 3:d821-833.

24. Yoshizawa T, Handa Y, Uematsu Y, Takeda S, Sekine K, Yoshihara Y, Kawakami T, Arioka K, Sato H, Uchiyama Y, et al: Mice lacking the vitamin $D$ receptor exhibit impaired bone formation, uterine hypoplasia and growth retardation after weaning. Nat Genet 1997, 16(4):391-396.

25. Li YC, Pirro AE, Amling M, Delling G, Baron R, Bronson R, Demay MB: Targeted ablation of the vitamin $D$ receptor: an animal model of vitamin D-dependent rickets type II with alopecia. Proc Natl Acad Sci USA 1997, 94(18):9831-9835.

26. Jurutka PW, Bartik L, Whitfield GK, Mathern DR, Barthel TK, Gurevich M, Hsieh JC, Kaczmarska M, Haussler CA, Haussler MR: Vitamin D receptor: key roles in bone mineral pathophysiology, molecular mechanism of action, and novel nutritional ligands. J Bone Miner Res 2007, 22(Suppl 2):V2-10.

27. Sutton AL, MacDonald PN: Vitamin D: more than a "bone-a-fide" hormone. Mol Endocrinol 2003, 17(5):777-791.

28. White C, Gardiner E, Eisman J: Tissue specific and vitamin D responsive gene expression in bone. Mol Biol Rep 1998, 25(1):45-61 
29. St-Arnaud R: The direct role of vitamin D on bone homeostasis. Arch Biochem Biophys 2008, 473(2):225-230.

30. Panda DK, Miao D, Bolivar I, Li J, Huo R, Hendy GN, Goltzman D: Inactivation of the 25-hydroxyvitamin D 1alpha-hydroxylase and vitamin $D$ receptor demonstrates independent and interdependent effects of calcium and vitamin D on skeletal and mineral homeostasis. J Biol Chem 2004, 279(16):16754-16766.

31. Gutierrez S, Liu J, Javed A, Montecino M, Stein GS, Lian JB, Stein JL: The vitamin $D$ response element in the distal osteocalcin promoter contributes to chromatin organization of the proximal regulatory domain. J Biol Chem 2004, 279(42):43581-43588.

32. Paredes R, Arriagada G, Cruzat F, Villagra A, Olate J, Zaidi K, van Wijnen A, Lian JB, Stein GS, Stein JL, et al: Bone-specific transcription factor Runx2 interacts with the 1alpha,25-dihydroxyvitamin D3 receptor to upregulate rat osteocalcin gene expression in osteoblastic cells. Mol Cell Biol 2004, 24(20):8847-8861.

33. Shen $Q$, Christakos S: The vitamin D receptor, Runx2, and the Notch signaling pathway cooperate in the transcriptional regulation of osteopontin. J Biol Chem 2005, 280(49):40589-40598.

34. Arendt $D$ : The evolution of cell types in animals: emerging principles from molecular studies. Nat Rev Genet 2008, 9(11):868-882

35. Dean AM, Thornton JW: Mechanistic approaches to the study of evolution: the functional synthesis. Nat Rev Genet 2007, 8(9):675-688.

36. Wray GA: The evolutionary significance of cis-regulatory mutations. Nat Rev Genet 2007, 8(3):206-216.

37. Suzuki T, Suzuki N, Srivastava AS, Kurokawa T: Identification of cDNAs encoding two subtypes of vitamin $D$ receptor in flounder, Paralichthys olivaceus. Biochem Biophys Res Commun 2000, 270(1):40-45.

38. Craig TA, Sommer S, Sussman CR, Grande JP, Kumar R: Expression and Regulation of the Vitamin D Receptor in the Zebrafish, Danio rerio. $J$ Bone Miner Res 2008, 23(9):1486-96.

39. Gerstenfeld LC, Zurakowski D, Schaffer JL, Nichols DP, Toma CD, Broess M, Bruder SP, Caplan Al: Variable hormone responsiveness of osteoblast populations isolated at different stages of embryogenesis and its relationship to the osteogenic lineage. Endocrinology 1996, 137(9):3957-3968.

40. Endo I, Inoue D, Mitsui T, Umaki Y, Akaike M, Yoshizawa T, Kato S, Matsumoto T: Deletion of vitamin $D$ receptor gene in mice results in abnormal skeletal muscle development with deregulated expression of myoregulatory transcription factors. Endocrinology 2003, 144(12):5138-5144

41. Kerney R, Hanken J: Gene expression reveals unique skeletal patterning in the limb of the direct-developing frog, Eleutherodactylus coqui. Evol Dev 2008, 10(4):439-448.

42. Miura S, Hanaoka K, Togashi S: Skeletogenesis in Xenopus tropicalis: Characteristic bone development in an anuran amphibian. Bone 2008, 43(5):901-9.

43. Li N, Felber K, Elks P, Croucher P, Roehl HH: Tracking gene expression during zebrafish osteoblast differentiation. Dev Dyn 2009, 238(2):459-466.

44. Renn J, Winkler C: Osterix-mCherry transgenic medaka for in vivo imaging of bone formation. Dev Dyn 2009, 238(1):241-248.

45. Whitfield GK, Dang HT, Schluter SF, Bernstein RM, Bunag T, Manzon LA, Hsieh G, Dominguez CE, Youson JH, Haussler MR, et al: Cloning of a functional vitamin $D$ receptor from the lamprey (Petromyzon marinus), an ancient vertebrate lacking a calcified skeleton and teeth. Endocrinology 2003, 144(6):2704-2716.

46. Laue K, Janicke M, Plaster N, Sonntag C, Hammerschmidt M: Restriction of retinoic acid activity by $C y p 26 \mathrm{~b} 1$ is required for proper timing and patterning of osteogenesis during zebrafish development. Development 2008, 135(22):3775-3787.

47. Spoorendonk KM, Peterson-Maduro J, Renn J, Trowe T, Kranenbarg S, Winkler C, Schulte-Merker S: Retinoic acid and Cyp26b1 are critical regulators of osteogenesis in the axial skeleton. Development 2008, 135(22):3765-3774.

48. Nakashima K, de Crombrugghe B: Transcriptional mechanisms in osteoblast differentiation and bone formation. Trends Genet 2003, 19(8):458-466.

49. Fleming A, Sato M, Goldsmith P: High-throughput in vivo screening for bone anabolic compounds with zebrafish. J Biomol Screen 2005, 10(8):823-831.
50. Li YC, Bergwitz C, Juppner H, Demay MB: Cloning and characterization of the vitamin D receptor from Xenopus laevis. Endocrinology 1997, 138(6):2347-2353.

51. Ekins $S$, Reschly EJ, Hagey LR, Krasowski MD: Evolution of pharmacologic specificity in the pregnane $X$ receptor. BMC Evol Biol 2008, 8:103.

52. Li QL, Ito K, Sakakura C, Fukamachi H, Inoue K, Chi XZ, Lee KY, Nomura S, Lee CW, Han SB, et al: Causal relationship between the loss of RUNX3 expression and gastric cancer. Cell 2002, 109(1):113-124.

53. Meulemans D, Bronner-Fraser M: Insights from amphioxus into the evolution of vertebrate cartilage. PLOS ONE 2007, 2(8):e787.

54. Nam S, Jin YH, Li QL, Lee KY, Jeong GB, Ito Y, Lee J, Bae SC: Expression pattern, regulation, and biological role of runt domain transcription factor, run, in Caenorhabditis elegans. Mol Cell Biol 2002, 22(2):547-554.

55. Stricker S, Poustka AJ, Wiecha U, Stiege A, Hecht J, Panopoulou G, Vilcinskas A, Mundlos S, Seitz V: A single amphioxus and sea urchin runtgene suggests that runt-gene duplications occurred in early chordate evolution. Dev Comp Immunol 2003, 27(8):673-684.

56. Lu Z, Hanson K, DeLuca HF: Cloning and origin of the two forms of chicken vitamin D receptor. Arch Biochem Biophys 1997, 339(1):99-106.

57. Bookout AL, Jeong Y, Downes M, Yu RT, Evans RM, Mangelsdorf DJ: Anatomical profiling of nuclear receptor expression reveals a hierarchical transcriptional network. Cell 2006, 126(4):789-799.

58. Tuch BB, Li H, Johnson AD: Evolution of eukaryotic transcription circuits. Science 2008, 319(5871):1797-1799.

59. Arthur W: The emerging conceptual framework of evolutionary developmental biology. Nature 2002, 415(6873):757-764.

60. Eames BF, Allen N, Young J, Kaplan A, Helms JA, Schneider RA: Skeletogenesis in the swell shark Cephaloscyllium ventriosum. J Anat 2007, 210(5):542-554.

61. Kawasaki K, Buchanan AV, Weiss KM: Gene duplication and the evolution of vertebrate skeletal mineralization. Cells Tissues Organs 2007, 186(1):7-24

62. Nieuwkoop PD, Faber J: Normal Table of Xenopus laevis (Daudin). Utrecht, The Netherlands: North Holland Publishing Company 1967.

63. Low M, Sandoval D, Aviles E, Perez F, Nualart F, Henriquez JP: The ascorbic acid transporter SVCT2 is expressed in slow-twitch skeletal muscle fibres. Histochem Cell Biol 2009, 131(5):565-574.

64. Jowett $T$, Lettice $L$ : Whole-mount in situ hybridizations on zebrafish embryos using a mixture of digoxigenin- and fluorescein-labelled probes. Trends Genet 1994, 10(3):73-74.

65. Rochel N, Wurtz JM, Mitschler A, Klaholz B, Moras D: The crystal structure of the nuclear receptor for vitamin $\mathrm{D}$ bound to its natural ligand. $\mathrm{Mol}$ Cell 2000, 5(1):173-179.

doi:10.1186/1471-2148-10-78

Cite this article as: Marcellini et al:: Evolution of the interaction between Runx2 and VDR, two transcription factors involved in osteoblasto] genesis. BMC Evolutionary Biology 2010 10:78.

\section{Submit your next manuscript to BioMed Central and take full advantage of:}

- Convenient online submission

- Thorough peer review

- No space constraints or color figure charges

- Immediate publication on acceptance

- Inclusion in PubMed, CAS, Scopus and Google Scholar

- Research which is freely available for redistribution

Submit your manuscript at www.biomedcentral.com/submit
C Biomed Central 